\section{IJ§ER}

ISSN: 2149-5939
International Journal of Social Sciences and Education Research

Online, http://dergipark.gov.tr/ijsser

Volume: 1(2), 2015

\title{
Sinema filmlerinde gözetim ve iktidar ilişkilerinin inşası
}

\author{
Supervision and power relationship's construction in cinema films
}

\author{
Dilar Diken Yücel ${ }^{1}$
}

\begin{abstract}
Received Date: $01 / 02$ / 2015
Accepted Date: 01 / 04 / 2015

$\ddot{O} z$

Bu çalışmada, görünen her şeyin gözetlenebildiği günümüzde, gözetlemenin hangi amaçlar uğruna kim tarafindan yapıldı̆̆ ve gözetimin meydana getirdiği mahremiyet sorunları konu edilmiştir. Çalışmada gözetim kavramı, yaşamımızın her aşamasında var olan iktidar odakları ile ilişkilendirilerek sinema filmleri aracılığı ile incelenmiştir. Çalışmada gözetim kavramı Michel Foucault ve Jeremy Bentham 'ın yaklaşımları çerçevesinde ele alınmaktadır. Çalışmada, Bentham'ın gözetim kavramını mimarisine yansittı̆̆ "Panoptikon" hapishane projesi ve günümüzde Panoptikon kavramının tamamlayıcısı niteliğinde olan "Sinoptikon" ve "Süperpanoptikon" kavramlart incelenmiştir. Gözetim kavramın sosyal bilimlere kazandıran Foucault'un ise beden ve iktidar üzerine olan yaklaşımlarına yoğunluk verilmiștir. Çalışma ile gözetim kavramının sinema filmleri aracılığıyla tartışılması amaçlanmıştır. Gözetim ve iktidar ilişkilerinin filmlere nasıl yansıdı̆̆ını konu alan bu çalışma, yöntem olarak tarihsel ve göstergebilimsel analizden bir arada yararlanılmıștır. Çalışma kapsamında 2012 ve 2015 yılları arasında vizyona giren Açlık Oyunları film serisinin üç filmi incelenmiştir. Çalı̧̧manın hem sinema alanına hem de gözetim kavramı üzerine süren tartışmalara katkı sağlayacağı düşünülmektedir.
\end{abstract}

Anahtar sözcükler: Gözetim, iktidar, göstergebilim, mahremiyet, sinema

\begin{abstract}
This study's subject is about for which purposes and by whom the surveillance is done in these days. In this study, the concept of surveillance were examined through movies in relation with power structures existing at all stages of our lives. In this study, the notion of surveillance is discussed from the perspectives of Michel Foucault's and Jeremy Bentham's approaches. As a part of this study, Bentham's "Panopticon" prison project, which has an architectural design shaped according to the notion of surveillance, and terms of Sinopticon and Superpanopticon which are the complementary notions of "Panopticon" are analyzed. In addition to that, as the person who brought the term "surveillance" into social sciences, M. Foucault's approaches to power and body are at the focus of this study. The study aimed to discuss the films through the concept of surveillance. The study focusing on how films reflect the surveillance and power relations has benefited from a combination of historical and semiotic analysis as a method. Three films released in between 2012 and 2015 of The Hunger Games series have been studied in this research. The study is expected to contribute to both the field of cinema and the ongoing debates on the notion of surveillance.
\end{abstract}

Keywords: Surveillance, power, semiology, privacy, cinema

\section{Giriş}

Enformasyon çağı olarak da adlandırılan günümüzde, toplumsal yapı giderek gözetim toplumuna dönüşmektedir. Görünen her şeyin bilgisine ulaşma arzusunun temeli kuşkusuz oldukça eskilere dayanır. Gözetim olgusu üzerine düşünen Jeremy Bentham, Michel Foucault, George Orwell gibi isimlerden çok önce Platon, felsefesinin temeline görme duyusunu almıştır. Platondan

${ }^{1}$ Res. Assist., Gazi University, Faculty of Communication, ANKARA/TURKEY, dilardiken@gazi.edu.tr; $\underline{\text { dlra- }}$ 35@hotmail.com 
Diken Yücel, D. (2015). Supervision and power relationship's construction in cinema films. International Journal of Social Sciences and Education Research, 1 (2), 390-398.

günümüze aslında değişen sadece görme biçimlerimizdir. Gelişen teknoloji sayesinde artık insanoğlu küresel gözetleme olanaklarına sahip olmuştur.

Enformasyon teknolojilerinin gözetimin ayrılmaz bir parçası olduğuna inanan David Lyon'un belirttiği gibi bireyler artık bedenlerinden styrilıp sayısal kodlar haline gelmektedir(Dolgun,2008:28).Kişisel bilgilerimizin veri bankalarında depolandığı, yaptığımız her eylemin kayıt altına alındığı günümüzde "gözetim” çağımızın en önemli kavramlarından biridir. Peki neden ve kim tarafından gözetleniyoruz? Görülebilen her şeyin denetlenebilir olduğu gerçeği bizleri iktidar kavramı hakkında düşünmeye yöneltiyor. Bizi gözetleyen iktidar odakları toplumun her kesiminde mevcuttur. İktidar odakları varlıklarını sürdürebilmek için tarihin her döneminde gözetime başvurmuştur. Çünkü söz konusu iktidarların gözetimin, cezalandırmadan daha etkili olduğunu anlamaları uzun sürmemiştir.

Gözetim olgusunun geçmişi oldukça eskilere dayanır. Tarih boyunca insanlar, güvenliği ve toplumun refahını sağlamak amacıyla gözetlendiklerine inandırılmış ve böylece gönüllü olarak iktidarın gözetim nesnesi haline gelmişlerdir (Dolgun, 2008: 15).

Foucault'un, Hapishanenin Doğuşu, Deliliğin Tarihi, Büyük Kapatılma gibi eserlerinde kullandığı "Kapatılma" kavramı gözetimin temelinde kapitalist amaçlar olduğu gerçeğini gözler önüne sermektedir. Foucault, hapishanenin suçluları 1slah etmek gibi masum bir ilke uğruna kurulduğu, hastanelerin sadece hastalıklı bedenleri iyileştirmek amacıyla kurulduğu anlayışını ret eder. Foucault'a göre hapishaneler suçluları ıslah etmez aksine suçlulardan iktisadi olarak yararlanmayı hedefler. "'iktidarın Gözü'" adlı eserinde Foucault, hapishanelerin bu durumunu şu sözlerle açıklar: "Suça eğilimliler işe yarar. Örneğin cinsel zevk sömürüsünden elde edilebilecek kârda kullanılırlar: Günlük ve pahalı cinsel haz ile sermayeleştirme arasında aracılık görevi üstlenen suça eğilimliler sayesinde ancak mümkün olan devasa fahişelik kurumu on dokuzuncu yüzyılda bu şekilde yerleşebilmiştir." Ayrıca Foucault, 3.Napoleon'un iktidarını adli suçlulardan oluşan bir grup sayesinde elde ettiğini belirtiyor(Foucault, 2012:24).Aynı şekilde hastaneler, mevcut iktidar tarafından tehlikeli görülenlerin kapatıldığı ve rahatça gözetlenebildiği kurumlardir.

\section{Gözetim ile ilgili kavramlar}

\subsection{Panoptikon}

Gözetimin mimaride vücut bulduğu 'Panoptikon'” görünmeyenin görüneni gözetlediği Jeremy Bentham'a ait 1791 yılında oluşturulan bir hapishane projesidir. Panoptikon kavramının kökeni, Yunan mitolojisine dayanmaktadır. Bu kavramın Argus Panoptes adlı zaman zaman dört gözlü, zaman zaman ise tüm vücudu gözlerle kaplı olarak tasvir edilen aynı anda birden çok şeyi görebilen bir karakterden esinlenerek oluşturulduğuna inanılır. Panoptes' in en önemli özelliği ise görülmeden, görebilir olmasıdır (Pimenta,2008:267-268).

Panoptikon, merkezinde geniş pencereleri ve gözetleme kulesi bulunan halka biçiminde bir yapıdır. Bina hücrelere bölünmüştür ve bu hücrelerin biri içeri bakan ve kuleninkilere karşı gelen, diğeri de dışarı bakan ve ışık alan ikişer penceresi vardır. Ayrıca hücrelerin arasındaki duvarlar sayesinde mahkûmların birbirileri ile olan iletişimi de engellenmiştir.

Tüm bu fiziksel özellikler sayesinde kuleye yerleştirilen tek bir gözcü tüm hücrelerdeki mahkûmları gözetleyebilmektedir. Ayrıca mahkûmlar kendilerini gözetleyeni göremedikleri için sürekli gözetim altındaymış gibi davranırlar ve bu sayede sürekli işleyen bir iktidar yaratılmış 
Diken Yücel, D. (2015). Sinema filmlerinde gözetim ve iktidar ilişkilerinin inşası. International Journal of Social Sciences and Education Research, 1 (2), 390-398.

olur. Bu hapishane modelinde görünürlük Foucault’un belirttiği gibi aslında bir “tuzak”tır (Foucault, 2013:295-296).

\subsection{Süperpanoptikon}

Gelişen teknoloji sayesinde küresel bir gözetimden söz etmek mümkün hale gelmiştir. Bu noktada Panoptikon kavramı tek başına gözetim gerçekliğini ifade etmede yetersiz kalmıştır. Bu sebeple, Panoptikon kavramını destekleyici bir kavram olan Süperpanoptikon kavramı oluşturulmuştur. Mark Poster, geliştirmiş olduğu bu kavramı şu şekilde tanımlar; "Bugünkü iletişim devreleri ve veri tabanları Süperpanoptikon'u bir kurum olarak yaratmaktadır. Burası öyle bir kurumdur ki duvarsız, penceresiz, gözetleme kulesiz bir gözetim yeridir” (akt: King,2001: 46-47).

Günümüzde bireylerin gönüllü olarak oluşturduğu süperpanoptikon ortamından kendilerini soyutlamaları mümkün değildir. Kredi kartı ile yaptığımız alışverişlerde arkamızda bıraktığımız iz, telefon konuşmalarımızın kayıt altına alınabilir oluşu, mobese kameraları tarafından saat kaçta nerede olduğumuzun tespit edilebildiği, sosyal medya hesaplarımız sayesinde kolayca erişilebilen kişisel verilerimizin varlığı, 11 haneli kimlik numaralarımız sayesinde adeta kodlandığımız bir ortamda Süperpanoptikon'un birer parçası olduğumuz inkâr edilemez. Elektronik Panoptikon olarak da adlandırabileceğimiz Superpanoptikon sayesinde bireylerin görünürlüğ̈̈ artmış ve adeta şeffaflaşmıştır. Bu şeffaflıktan faydalanan elbette ki sadece ekonomi değildir. İktidar da bu görünürlük sayesinde devamlılı̆ğını sürdürmeyi amaçlar.

\subsection{Sinoptikon}

Panoptikon ve süperpanoptikon kavramlarını açıklamak için kullanılan bir diğer destekleyici kavram ise "Sinoptikon" olmuştur. Kitle iletişim araçları kullanılarak gerçekleştirilen Sinoptikon da ise Panoptikon'un aksine çoğunluk, azınlığı izler.

Thomas Mathiesen geliştirdiği bu kavramın temeline televizyonu koyar. Mathiesen, panoptikon ile yerelleştirilmiş olan bireylerin sinoptikon sayesinde küreselleştiğinden söz eder. Üstelik Panoptikondan farklı olarak Sinoptikonda gözetime katılma, zorunlu değil gönüllü olarak gerçekleştirilen bir eylemdir. Gözetimin bir eğlence unsuru olan televizyon gibi kitle iletişim araçları vasıtasıyla yapılması, artık zorlayarak değil eğlendirerek etki altına alma stratejisini geliştirmiştir. Belirli iktidar odakları tarafından seçilmiş olan kişilerin yaptığı televizyon programları eğlendirirken etki altına alıp denetlemeyi amaçlamaktadır.

\section{Gözetim ve iktidar ilişkisi}

İktidarın gözetim işlevinden bahsetmeden önce iktidar kavramı üzerinde kısa bir açıklama yapmak yerinde olacaktır. İktidar kavramına farklı perspektiften bakan birçok yaklaşım bulunmaktadır. Örneğin Marx, iktidar kavramını açıklarken düşüncesinin temeline sınıf çatışması, sömürü, emeğin yabancılaşması gibi kapitalist toplumlarla içkinleşmiş olan kavramları koymaktadır. İktidara burjuva sınıfının kapitalist uğraşları çerçevesinde bakan Marx, böylece bu kavrama ideoloji penceresinden bakmayı seçmiştir.

Foucault'a göre ise, iktidarı sadece bir baskı unsuru olarak zihnimizde canlandırmak bizleri yanlış düşünmeye sevk eder. Bu düşüncesini şu sözlerle destekler; 'İktidarın işleyişinden söz ettiğimde yalnızca devlet aygıtı sorununa, yönetici sınıf, hegemonik kastlar sorununa gönderme yapıyor değilim, bireylerin gündelik davranışlarında, bedenlerine varıncaya kadar işleyen giderek daha da incelen, tüm mikroskobik iktidarlar dizisine gönderme yapıyorum'” ( Foucault, 2012:48). 
Diken Yücel, D. (2015). Supervision and power relationship's construction in cinema films. International Journal of Social Sciences and Education Research, 1 (2), 390-398.

İktidarı, sadece siyasi iktidar olarak algılayan sı̆g bir yaklaşımdan ziyade, insan vücudunun kılcal damarlarına dahi nüfuz edebilecek adeta gündelik yaşamın her anında var olan bir olgu olarak düşünmek daha doğrudur ( Foucault,2012:23). Foucault'a göre beden iktidarın öznesi durumundadır. Bu düşüncesi ise biyo-iktidar olarak kavramsallaştırmıştır. Foucault, iktidar tanımı yaparken geleneksel iktidar ve biyo-iktidardan söz eder. Geleneksel iktidarı "hukuki-söylemsel" olarak tanımlar ve bu iktidar modelinin yasa, yasaklama ve itaat sistemi üzerine kurulduğundan bahseder. Fakat on yedinci yüzyıl sonunda batı toplumlarında geleneksel iktidar anlayışının, yerini biyo- iktidar olarak tanımladığı pozitif iktidara bıraktığını belirtir. Biyo-iktidar'ın insan yaşamına iki yönlü müdahale ettiğini söyleyen Focault’a göre ilk müdahale biçimi bedenini disipline eden iktidar biçimidir. Bu iktidar biçiminde amaç insan bedenini disipline edip daha verimli hale getirmektir. Bu işlevi yerine getirmek için ise hastaneleri, hapishaneleri, okulları kullanır. Nüfusun biyo-politiği olarak adlandırdığı diğer müdahale biçiminde ise, nüfusu düzenleyici bir denetim söz konusudur. Kapitalizmin gelişmesine oldukça katkı sağlayan biyo-iktidar, Foucault'a göre burjuva toplumunun en büyük buluşudur (Foucault, 2014:16-17).

\section{Açlık oyunları film serisinin incelenmesi}

Çalışma kapsamında incelenmek üzere, Suzanne Collins'in Açlık Oyunları adlı üçleme romanından sinemaya uyarlanan film serisi seçilmiştir. Seçilen film serisi senaryosunda iktidarın gözetimini ve bu gözetim sonucu oluşan olumsuz ütopyaları içermektedir.

Açlık oyunları film serisi üç filmden oluşmaktadır. 23 Mart 2012 vizyon tarihli serinin ilk filmi “Açlık Oyunları”dır. Film Suzanne Collins’in film ile aynı adı taşıyan 'Açlık Oyunları' adlı romanından uyarlanmıştır. Karma bir tür sınıfına koyabileceğimiz film, senaryosunda aksiyon, bilimkurgu, dram türlerinin özelliklerini barındırmaktadır. Gary Ross'un yönetmenliğini yaptığı filme 78 milyon dolar bütçe harcanmıştır. Filmin gişe hasılatı ise 691,247,768 \$ dır( http://www.imdb.com/title/tt1392170/,10.09.2015).

Film Panem denilen distopyanın (açlık, savaşlar...) karakteristik özelliklerini taşıyan bir ülkede geçmektedir. Panem, uzun zaman önce Kuzey Amerika olarak bilinen fakat savaşlar ve doğal afetler sonucu yok olan bir bölgede kurulmuştur (Egan,2012:8). Ülke capitol adı verilen başkent ve buna bağlı 13 mıntıkadan oluşmaktadır. Fakat 13. Mıntıka capitol'e karşı başlattığı isyan sonucu yok edilmiştir. Capitol de yaşayan halk lüks ve abartılı bir yaşam tarzına sahiptir. Mıntıkada yaşayan halk ise tam tersi. Mıntıka halkı bir yandan capitol'un ezici baskısı karşısında ayakta kalmaya çalışıyor bir yandan da açlık ve yoksullukla mücadele ediyordu. Panemdeki mıntıkaların bir özelliği de birbirlerinden tamamen tecrit edilmiş şekilde yaşamalarıydı. Capitol tarafından kendilerine çizilen sınırlardan dışarı çıkmaları yasaktı. Aksi şekilde davranan en ağır cezaya çarptırılıyordu. Mintıkalarla ilgili havadisleri Capitol'e bildiren muhafızlar bulunuyordu. Böylece halk sürekli denetim ve gözetim altında tutuluyordu.

Filme adını veren 'Açlık Oyunları' ise her yıl Capitol tarafından gerçekleştirilen bir televizyon şovudur. Fakat bu sadece Capitol halkını eğlendirir. Çünkü şov mıntıkaların Capitol'e karşı isyana kalkışmaması için verilen bir gözdağı niteliğindedir.13.mıntıkanın gerçekleştirmiş olduğu isyan sonucu capitol diğer mıntıkalara ihanet antlaşması imzalatmıştır. Bu antlaşmaya göre her yıl tüm mıntıkalardan birer erkek ve birer genç kız haraç olarak, capitol tarafindan yaratılan ölümcül bir arenada sadece tek bir kazananı olacak ölüm yarışına katılacaktır. Bu sayede Capitol iktidarını sürdürmeyi amaçlamaktadır. 
Diken Yücel, D. (2015). Sinema filmlerinde gözetim ve iktidar ilişkilerinin inşası. International Journal of Social Sciences and Education Research, 1 (2), 390-398.

Serinin tüm filmleri ortak çatışmalar üzerinde kurgulanmıştır. Bu çatışmalar ise aşağıdaki tabloda gösterilmiştir.

Tablo 1. Film metnindeki ortak çatışmalar

\begin{tabular}{|l|l|}
\hline Yoksul & Zengin \\
\hline Gözetlenen & Gözetleyen \\
\hline Tutsak & Özgür \\
\hline Halk & İktidar \\
\hline
\end{tabular}

Serinin ilk filmi olan Açlık Oyunlarında, başrol oyuncuları Katniss ve Peeta'ın Açlık Oyunlarındaki mücadeleleri konu alınırken, devam filmlerinde ise oyunlara son vermek için iktidara karşı bir direniş işlenmiştir. Filmler incelenirken, kesit alma yoluyla görseller belirlenmiş ve bu görseller çevremizde bulunan anlamlar evrenini açıklamaya yardımcı olan göstergebilimden faydalanılarak yorumlanmıştır.

Tablo 2. Açlık Oyunları Filmi Göstergeleri

\begin{tabular}{|l|l|l|}
\hline \multicolumn{1}{|c|}{ Gösterge } & \multicolumn{1}{c|}{ Gösteren } & \multicolumn{1}{c|}{ Gösterilen } \\
\hline Nesne & Takip Cihazı & Gözetim Teknolojileri \\
\hline İnsan & Kan Alma, Sayım ve Kayıt & Gözetimin Nesnesi ' İnsan' \\
\hline Nesne & Alaycı Kuş Broşu & Özgürlük Umudunun Sembolü \\
\hline
\end{tabular}

Resim 1: Takip Cihazı

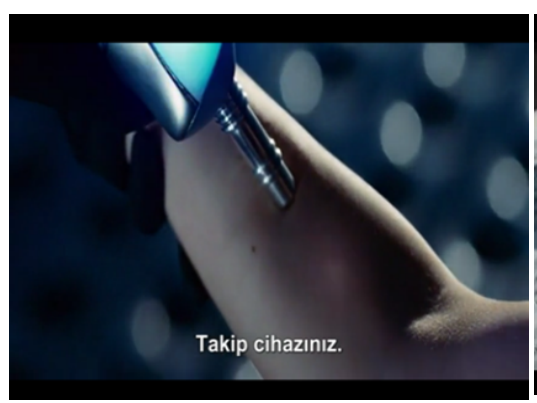

Resim 2: Kan Alma İşlemi Resim 3: Alaycı Kuş Broşu

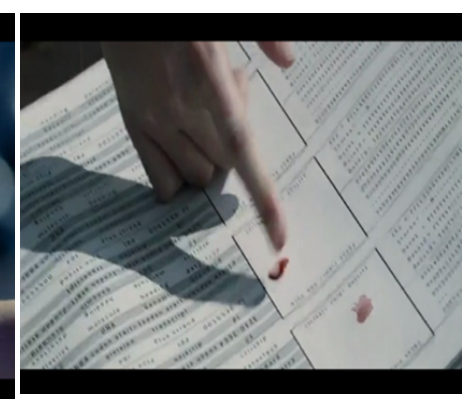

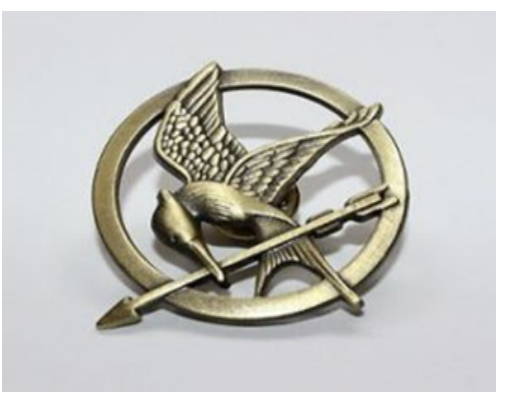

Resim 1'de Capitol'un Açlık Oyunları arenasına gönderdiği haraçları kolayca gözetleyebilmesini sağlayan takip cihazı görülmektedir. Haraçların vücuduna yerleştirilen bu cihaz Süperpanoptikon'un işleyişine dair bir örnektir. Gelişmiş teknolojik cihazlar yardımı ile Capitol geniş bir gözetim ağına sahiptir. İkinci resimde ise, gözetimin kayıt altına alma özelliğine vurgu yapılmaktadır. Alınan kan örnekleri ve sayım defteri ile bilgi toplama yoluyla gözetim yapılmaktadır. Üçüncü resimde ise Alaycı Kuş broşu görülmektedir. Bu broş aynı zamanda serinin 3.filminede adını vermiştir. Katniss'e hediye edilen bu broş zamanla onunla özdeşleşmiş ve özgürlük için umudun sembolü olmuştur. Aynı zamanda broştaki kuş figürünün ağzında ok tutuyor olması Katniss ile özdeşleşen bir diğer özelliğidir. Zira Katniss Açlık Oyunlarında okçuluğu sayesinde başarılı olmuştur.

Serinin ikinci filmi olan Ateşi Yakalamakta ise capitol'e karşı direnişin ilk adımları atılmaktadır. 
Diken Yücel, D. (2015). Supervision and power relationship's construction in cinema films. International Journal of Social Sciences and Education Research, 1 (2), 390-398.

Tablo 3. Ateşi yakalamak film göstergeleri

\begin{tabular}{|l|l|l|}
\hline \multicolumn{1}{|c|}{ Gösterge } & \multicolumn{1}{|c|}{ Gösteren } & \multicolumn{1}{c|}{ Gösterilen } \\
\hline İnsan & Katniss ve Gale'in yakın görüntüsü & Kişisel Mahremiyet Alanlarının İhlali \\
\hline Nesne & Kan Dolu Kadeh & İktidarın Şiddetten Beslenmesi \\
\hline Nesne & İdam Edilmiş Robot & Senatoya Başkaldırı \\
\hline
\end{tabular}

Resim 4: Katniss ve Gale Resim 5: Başkan Snow Resim 6: İpe Asılan Robot

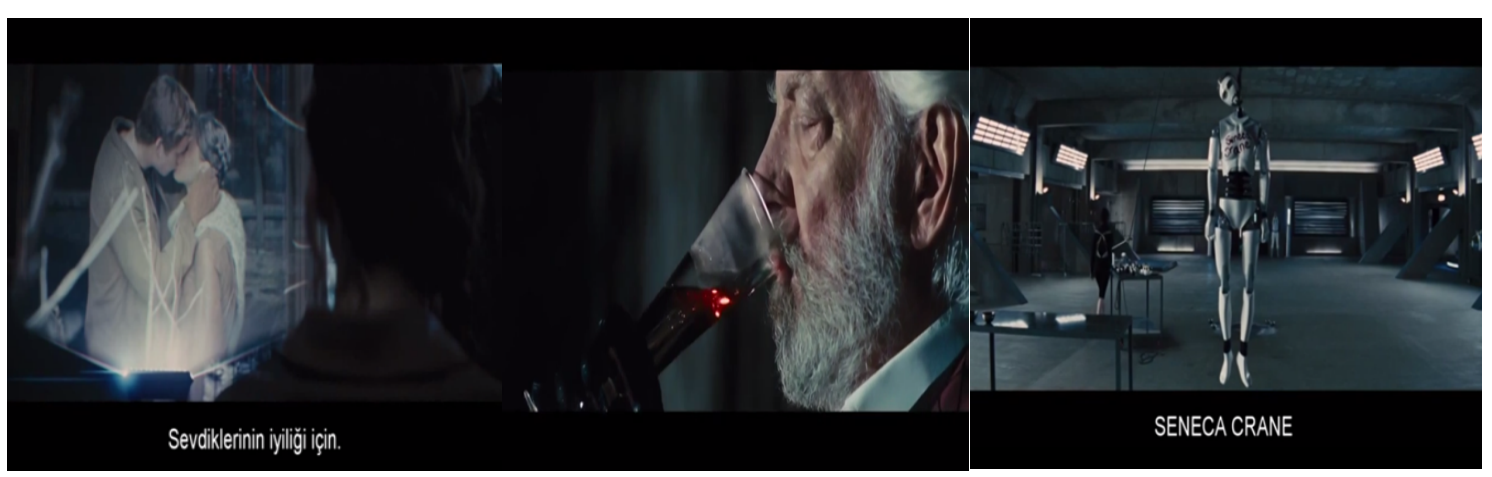

Resim 4'de Başkan Snow, Katniss'e Gale ile olan görüntüsünü izletiyor ve sevdiklerinin iyiliği için ondan uzak durması gerektiği konusunda uyarıyor. Bu diyalog Katniss'e mıntıkada her an izlendiği gerçeğini bir kez daha hatırlatıyor. Beşinci görselde ise, Başkan Snow'un yani iktidarın önce beyaz şarap ile dolu olan kadehinin bir yudum içince kan ile dolduğu sahne görülüyor. Snow'un kan dolan kadehi iktidarını sürdürebilmek için mıntıkadaki masum halkın kanı ile beslendiğini sembolize ediyor. Seçilen diğer görselde ise, Katniss'in bir robotu boynundan ipe ast1ğını görüyoruz. Bu eylemi ile Katniss senatoya ve Snow'a bir nevi başkaldırmış oluyor. Mıntıka halkının tıpkı robotlar gibi verilen komutlar doğrultusunda hayat sürmesini isteyen başkan Snow'a, bir şeylerin değișeceği mesajı veriliyor.

Serinin son filmi olan Alaycı Kuş'un vizyona giren ilk bölümünde ise, capitol'e karşı gerçekleştirilecek olan isyanın hazırlıkları ve Katniss'in isyanın yüzü oluşu anlatılmaktadır.

Tablo 4. Alaycı kuş film göstergeleri

\begin{tabular}{|l|l|l|}
\hline \multicolumn{1}{|c|}{ Gösterge } & \multicolumn{1}{|c|}{ Gösteren } & \multicolumn{1}{c|}{ Gösterilen } \\
\hline İnsan & 13.Mıntıkanın kadın Başkanı & Feminizm \\
\hline Nesne & Katniss'in Propaganda Videoları & $\begin{array}{l}\text { Sinoptikon'un propaganda aracı } \\
\text { olarak işleyişi }\end{array}$ \\
\hline
\end{tabular}

Resim 7: 13.Mıntıkanın Başkanı

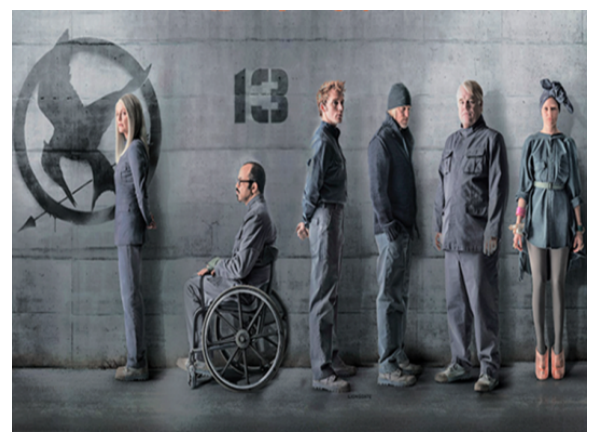

Resim 8: Katniss'in propaganda videosu

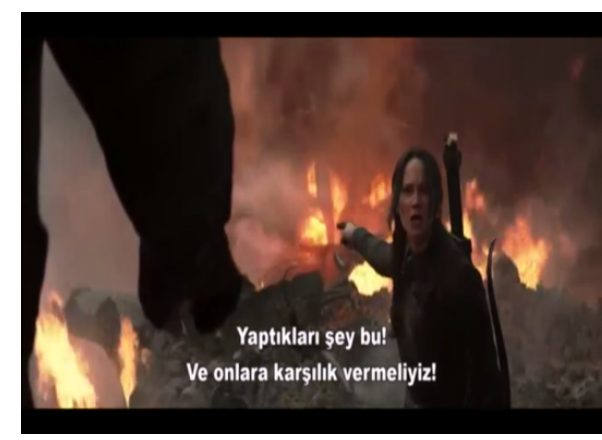


Diken Yücel, D. (2015). Sinema filmlerinde gözetim ve iktidar ilişkilerinin inşası. International Journal of Social Sciences and Education Research, 1 (2), 390-398.

Serinin üçüncü filminden seçilmiş olan yedinci görselde en ön sırada, Capitol'e karşı savaş açan 13. mıntıkanın kadın başkanını görüyoruz. Filmde direnişin öncüsünün bir kadın olması ve direnişin yüzü olması için Katniss'i seçmesi feminizmin göstergeleridir. Görselde kadın başkanı kendinden emin bir duruşa sahip olarak görüyoruz. Ayrıca Alaycı Kuş metaforu bu görselde de mevcuttur. Alaycı kuş sembolünün önünde duran başkanın direnişte bu sembolden destek aldığı düşünülebilir. Filmden seçilen ikinci görselde ise, Katniss'in direnişin propagandasını yapmak amacıyla çektiği videolarından bir sahne görüyoruz. Bu sahne, Sinoptikon kavramının işleyişinin bir örneğini teşkil etmektedir. Görselde Katniss, Capitol'un bombaladığı mıntıkalardan birindeki korkunç manzarayı izleyicilere işaret ediyor ve Capitol'un yıkıcı, despot yönetimine bir dur demenin zamanın geldiğini söylüyor.

\section{Sonuç}

Çalışma kapsamında incelenen Açlık Oyunları film serisinde, gözetimle ilgili açıklamış olan kavramların birer karşılığını görmek mümkündür. Örneğin, Capitol'e bağlı olan mıntıkalar birer Panoptikon örneği olabilirler. Zira tıpkı Panoptikon'da olduğu gibi bir merkez güç tarafından sürekli gözetime maruz bırakılmışlardır. Ayrıca tıpkı hapishane sınırları gibi mıntıkalarında sınırları vardır, bu sınırlardan çıkış ve dış dünya ile iletişim yasaktır. Diğer yandan Capitol'un uyguladığı gözetim pratikleri Süperpanoptikon kavramı ile ilişkilendirilebilir. Tıpkı Süperpanoptikon da olduğu gibi Capitol'de gelişen enformasyon teknolojileri ile gözetimi gerçekleştirmektedir. Sinoptikon kavramı ise, filmdeki Açlık Oyunları televizyon şovu ile karşılığını bulabilir. Çoğunluğun azınlığı izlediği Sinoptikonda olduğu gibi söz konusu televizyon şovu ile de kalabalık bir kitle tek kişi kalana dek 24 haraç’ı izlemektedir.

Çalışmada gözetim olgusunun, film metninde hem metaforlar yardımıyla hem de doğrudan işlendiği tespit edilmiştir. Seçilen filmlerde gözetimin, iktidarların devamlılıklarını sağlamada en önemli silahlarından biri olduğu fakat aynı zamanda toplumdaki mahremiyet olgusunu yok ettiği saptanmıştır. Ayrıca filmlerin metninde iktidarın gözetim dayatmasına karşı bir direniş söz konusudur. Serinin son filminin kapanışı izleyiciye direnişin devam ettiği mesajını yine bir metaforla (Snow'un beyaz gülleri) verir. Fakat filme uyarlanan romandan direnişin başarılı olduğu bilinmektedir.

\section{Kaynakça}

Dolgun, U. (2008). Şeffaf Hapishane Yahut Gözetim Toplumu. Ankara: Ötüken Neşriyat

Egan, K. (2012). Açlık Oyunları Dünyası.(1).(Çev. Tezcan, S., S.).İstanbul: Pegasus Yayıncılık.

Foucault, M. (2012). İktidarın Gözü.(3).(Çev. Ergüden, I.).İstanbul: Ayrıntı Yayınları

Foucault, M. (2013). Hapishanenin Doğuşu.(5).(Çev. Kılıı̧bay, M.A.).Ankara: İmge Kitabevi

Foucault, M. (2014). Özne ve İktidar.(4).(Çev. Ergüden, I., Akınhay, O.).İstanbul: Ayrıntı Yayınları

King, L. (2001).Information, Society and the Panopticon, The Western Journal of Graduate Research, 10 (1), 40-50.

Pimenta, E. (2008). Low Power Society. E-Book

---------, http://www.imdb.com/title/tt1392170/,10.09.2015

-,http://www.emanuelpimenta.net/lowpower/download/english.html, E.T. 10.09.2015.

--------, http://www.hdfilmsaati.org/aclik-oyunlari-izle.html 
Diken Yücel, D. (2015). Supervision and power relationship's construction in cinema films. International Journal of Social Sciences and Education Research, 1 (2), 390-398.

\section{Extended abstract in English}

This study's subject is about for which purposes and by whom the surveillance is done in these days. In this study, the concept of surveillance was examined through movies in relation with power structures existing at all stages of our lives.

Starting from the phenomenon of surveillance, which is old as human history, the notion of surveillance is discussed from the perspectives of Michel Foucault's and Jeremy Bentham's approaches. As a part of this study, Bentham's "Panopticon" prison project, which has an architectural design shaped according to the notion of surveillance, and terms of Sinopticon and Superpanopticon which are the complementary notions of "Panopticon" are analyzed. In addition to that, as the person who brought the term "surveillance" into social sciences, M. Foucault's approaches to power and body are at the focus of this study. The borders of personal privacy are getting vanished since the individuals have been begun to seen as numeric codes, not as human beings.

The study aimed to discuss the films through the concept of surveillance. The study focusing on how films reflect the surveillance and power relations has benefited from a combination of historical and semiotic analysis as a method. Three films released in between 2013 and 2015 of The Hunger Games series have been studied in this research. Movie series are adapted from the 'Hunger Games' novel by Suzanne Collins carrying the same name with the movie. Movie that can be classified as a mixed genre contains adventure, science-fiction and drama features. Directed by Gary Ross, the movie was budgeted for 78 million dollars. Gross of the movie is $\$$ $691,247,768$.

In the first movie of the series, Hunger Games, a dystopian country, a despotic government and a constantly observed community are included in the plot. The most important weapon of the government that exercises power on the community and establishes control through monitoring is the reality TV show called Hunger Games. Hunger Games are organized as a threaten for the public under the ruling by the government.

Each year a girl and a boy is selected from the districts for this show to participate in the Hunger Games and forced to survive in the play field until one person is left alive. In the second movie of the series, Catching Fire, the plot has focused on attempts to end the Hunger Games that are imposed by the government. Challenging the government and changing the rule of the competition, Katniss becomes the symbol of the hope light required for the freedom of the districts. Katniss says in case it's not allowed for two persons to win the competition, she will commit suicide with Peeta, her friend from the same district, and thus there won't be any winner in the competition. Government has perceived this move as a rebellion and increased the surveillance on the public. In the first part of the last movie of the series, Mockingjay that has come out, the plot has focused on the organization of the rebellion to be started against the government. Katniss is chosen as the face of the rebellion and tried to organize the people in the districts for the rebellion by shooting propaganda videos. These videos are one of the application areas of Synopticon, an important factor of the surveillance. As in Synopticon where majority monitors the minority through mass media, districts composing the majority have monitored Katniss through these videos. Thus, many people has been reached in a short time and support groups have been created for the rebellion. 
Diken Yücel, D. (2015). Sinema filmlerinde gözetim ve iktidar ilişkilerinin inşası. International Journal of Social Sciences and Education Research, 1 (2), 390-398.

It was determined in the examined movies, surveillance was adopted by the people forcefully by the despotic government. Surveillance practices applied by using force have intervened in even the right to live of individuals in time. In such an environment, people has chosen the resistance against the surveillance and succeeded in this. Besides, as per the scenario, the fact that the person leading the resistance is a woman and again a woman is selected as the face of the resistance displays the feminist approach underlying the movie script. The examined movie scripts include panopticon, superpanopticon and synopticon together. The person immured in the districts in the move resembles the Panopticon jail. To go beyond the district borders and to communicate with the surrounding districts are forbidden. On the other hand, surveillance practices applied by the government are like an extension of superpanopticon. As in the superpanopticon implying the surveillance conducted by using advanced technologies, the government in the examined movies also uses the advanced technology for the surveillance. Synopticon where the surveillance is conducted through mass media is used as television show in the movie.

The notion that a parallel between the rise of surveillance applications work with the development of information technology in mind, the assumption that one of the most important elements in ensuring the continuity of supervision of the power is tested. By the power of individuals through practical focus of surveillance beyond the films in this study we demonstrate how degree of privacy boundaries justified. 